REVISTA CHILENA DE LITERATURA

Noviembre 2015, Número 91, 51-70

\title{
TÉ, MARGARINA Y AUSTERIDAD. NICANOR PARRA EN LA POSTGUERRA INGLESA
}

\author{
Niall Binns \\ Universidad Complutense de Madrid \\ nbinns@filol.ucm.es
}

RESUMEN / ABSTRACT

El artículo estudia el impacto que tuvo en la obra de Nicanor Parra su estancia de dos años en la Universidad de Oxford entre 1949 y 1951, en una época marcada por las secuelas socioeconómicas de la Segunda Guerra Mundial, por la crisis de la identidad británica provocada por la pérdida de protagonismo internacional y el desmantelamiento del Imperio, y por las amenazas cada vez más notorias de la recién iniciada Guerra Fría. El análisis se centra en "Preguntas a la hora del té", un texto de la primera sección de Poemas y antipoemas (1954) que fue escrito aparentemente en Oxford, y plantea tanto un comentario de algunas lecturas canónicas como una nueva interpretación "inglesa" del poema.

Palabras clave: Nicanor Parra, Poemas y antipoemas, Oxford, racionamiento, Guerra Fría.

The article studies the impact on Nicanor Parra's poetry of the two years he spent in Oxford University between 1949 and 1951, in an era marked by the socio-economic repercussions of the Second World War, by the crisis in British identity provoked by the loss of international prominence and the dismantling of the Empire, and by the growing threat of the recently initiated Cold War. The analysis centres on "Preguntas a la hora del té", a text from the first section of Poemas y antipoemas (1954) which was apparently written in Oxford, and offers both a commentary on canonical readings and a new "English" interpretation of the poem.

KEY WORDS: Nicanor Parra, Poemas y antipoemas, Oxford, Rationing, Cold War. 
En el último número de la revista británica Poetry Nation Review, el poeta inglés J.S. Tennant publicó "Letter from Chile", una breve y alucinada semblanza escrita después de visitar a Nicanor Parra en su casa de Las Cruces en mayo de 2014, junto al ensayista canadiense John Ralston Saul y con Antonio Skármeta como cicerone, en una fallida misión de pedir ayuda para hacer revivir el PEN Club chileno ${ }^{1}$. Parra entró al salón para recibirlos arrastrando los pies, abrazó a Skármeta y se sentó, cabizbajo, mirando el piso y sin abrir la boca mientras oía hablar sobre el PEN. No mostró interés ninguno hasta que descubriera la procedencia de Tennant:

Fue solo cuando mencioné que había viajado desde Londres que de repente se animó, me miró y habló, ahora en inglés: “¿Eres británico? ¿De dónde?". Cuando respondí que era de Yorkshire golpeó su bastón contra el suelo, se le avivaron los ojos y agarró mi rodilla con la mano: "Yo estuve una vez en Bradford..." (7)

A partir de ese momento, en un inglés "impecable" (faultless English), Parra reveló toda su fascinación por la cultura británica en anécdotas de sus años en Oxford y citas fervorosas de Shakespeare. Tennant quedó evidentemente asombrado por la energía y la excentricidad de un poeta que estaba a punto de cumplir cien años (el asombro crecería, hacia el final de la visita, cuando Parra se levantó ante los invitados para bailar una cueca):

[Parra] empezó a pasar lista a sus profesores de la época en que estudiaba Cosmología en Oxford a finales de los años cuarenta, me preguntó si yo había estudiado en Oxford y antes de que pudiese contestar recitó de memoria la ecuación de la Ley de Hubble mientras golpeaba su bastón pidiendo a gritos que le trajeran vino y té: "¿Tomamos té o nos acribillamos a tiros? ¡NADA de azúcar en mi té, Rosita! Soy inglés". Ninguno de nosotros consiguió meter baza mientras comparaba su posición como padre de familia con la del Rey Lear y citaba a voleo a Hamlet, Polonio y largas secciones de

\footnotetext{
Debo el conocimiento de este texto al siempre generoso poeta y ensayista Jordi Doce.

"It was only when I mentioned that I'd travelled from London that he suddenly became animated and turned to me and spoke, in English now, 'You're British? Where from?' When I replied that I come from Yorkshire he rapped his stick on the floor, his eyes quickened, gripping my knee with his hand: 'I went to Bradford once...".
} 
El judio de Malta y Las alegres comadres de Windsor, con el dedo índice levantado y temblando en el aire (7) ${ }^{3}$.

La disyuntiva entre tomar té y acribillarse a tiros es antológica y una buena muestra de lo que Parra podría concebir como la civilidad inglesa: el don de evitar la beligerancia verbal y física mediante una ceremonia tan decorosamente social como la de compartir una taza de té. Igualmente sugerente es el momento en que se dirige en inglés a su empleada Rosa Avendaño: "NO sugar in my tea, Rosita! I'm English". Hace recordar que en esos años poéticamente decisivos en que Parra estudió en Oxford -entre septiembre de 1949 y junio de $1951-^{4}$, estaba aún en vigor el racionamiento de azúcar (al igual que otras comodidades) que se había puesto en marcha a comienzos de la Segunda Guerra Mundial. Una generación de ingleses se había acostumbrado a beber té sin azúcar.

\section{PREGUNTAS A LA HORA DEL TÉ}

Me interesa la relación entre Parra y el té a raíz de uno de los poemas más olvidados de la primera sección de Poemas y antipoemas, "Preguntas a la hora del té":

\footnotetext{
"He then made a roll-call of his professores from when he was studying cosmology at Oxford in the late 1940s, asked me if I went to Oxford, and before I could answer reeled off the equation for Hubble's law while banging his stick and shouting for wine and tea to be brought. "Shall we take tea, or shoot one another? NO sugar in my tea, Rosita! I'm English." None of us could get a word in edgeways as he likened his position as paterfamilias to that of King Lear, haphazardly quoting Hamlet, Polonius and long sections from The Jew of Malta and The Merry Wives of Windsor with his index finger raised and quivering".

"Llegué a Inglaterra el año 49 y allí estudié a los poetas metafísicos. Me olvidé de mis deberes académicos y quise estudiar por mi cuenta poetas como John Donne, y no tan solo a los poetas metafísicos, sino que también a Blake. Recuerdo que de John Donne me hizo gran impresión esa frase con que comienza uno de los sonetos de él: 'Muerte, no seas orgullosa'. Tal vez allí me hice plenamente consciente del oficio del poeta. En Inglaterra, no en Estados Unidos [donde Parra cursó estudios de postgrado en la Universidad de Brown entre 1943 y 1945]. Yo diría que hasta esos poemas, 'La víbora', 'La trampa', 'Los vicios del mundo moderno' [publicados en 1948 en la antología 13 poetas chilenos de Hugo Zambelli], están escritos todavía en una etapa de relativa inconsciencia. En cambio 'Las tablas', 'Soliloquio del individuo', escrito todavía con el método de la escritura automática, están escritos en Inglaterra" (Morales 72).
} 
Este señor desvaído parece

Una figura de un museo de cera;

Mira a través de los visillos rotos:

Qué vale más, ¿el oro o la belleza?

¿Vale más el arroyo que se mueve

O la chépica fija a la ribera?

A lo lejos se oye una campana

Que abre una herida más, o que la cierra:

¿Es más real el agua de la fuente

$\mathrm{O}$ la muchacha que se mira en ella?

No se sabe, la gente se lo pasa

Construyendo castillos en la arena:

¿Es superior el vaso transparente

A la mano del hombre que lo crea?

Se respira una atmósfera cansada

De ceniza, de humo, de tristeza:

Lo que se vio una vez ya no se vuelve

A ver igual, dicen las hojas secas.

Hora del té, tostadas, margarina,

Todo envuelto en una especie de niebla. (Parra 11)

Con su ritmo pausado, su tono sobrio y su carga de preguntas metafísicas, se trata de un texto anómalo en Poemas y antipoemas, un libro que es, a su vez, como ha señalado reiteradamente la crítica, anómalo también en su organización en tres secciones -de 7, 6 y 16 poemas respectivamente-, sobre todo porque el título parecería apuntar a una división binaria. Parra, en palabras muy citadas, justificó el reparto afirmando que el libro era, inicialmente, tres manuscritos, cada uno presentado al concurso del Sindicato de Escritores: el primero consistía en "poemas neorrománticos y posmodernistas" que mantenían "un diálogo o una oscilación entre la nostalgia y una ironía neorromántica"; conformaban el segundo textos "expresionistas" y "crispados", con "cierta brutalidad en la expresión, una amargura, una acidez y una agresividad"; el último, en cambio, correspondía a los antipoemas, de raíces kafkianas, surrealistas y chaplinescas (Morales 72).

Como acercamiento preliminar a "Preguntas a la hora del té", valdría la pena comentar las apreciaciones sobre el poema $-\mathrm{y}$, por extensión, sobre la primera sección de Poemas y antipoemas - de cuatro de los críticos más autorizados sobre la obra de Parra. Según la uruguaya Mercedes Rein, en su estudio pionero Nicanor Parra y la antipoesía (1970), la primera sección del libro se caracteriza por poemas de "un realismo sentimental, sin notas 
disonantes, con un lenguaje bastante convencional", cuyos endecasílabos con rima asonante (presentes en "Preguntas a la hora del té", "Hay un día feliz", "Es olvido" y "Se canta al mar") recuerdan a Bécquer, lo cual "no constituye precisamente un rasgo de audacia y modernidad". No hay, según Rein, "nada díscolo, nada fragmentario ni rebelde" en los siete textos de la primera sección, que se orientan "hacia un clima reflexivo, nostálgico, auténtico, que recuerda por momentos a Antonio Machado", sobre todo en "Preguntas a la hora del té", que es, sin embargo, "uno de los poemas más personales y auténticos de esta primera parte", y que elude las "convenciones un tanto retóricas" de otros como "Hay un día feliz" y "Se canta al mar" (Rein 22-23).

Marlene Gottlieb, en su libro de 1977 No se termina nunca de nacer: La poesía de Nicanor Parra, considera que hay en esa primera sección del libro de 1954 poemas "tradicionales", algunos de ellos "íntimamente autobiográficos", en los que están "totalmente ausentes [...] el sarcasmo y la rebeldía iconoclasta" de los antipoemas, mientras que la segunda sección está hecha de poemas "en transición o precursores del antipoema", con técnicas, temas y un tono satírico propios de los antipoemas, pero que conservan "un esquema métrico y la asonancia del romance". Ahora bien, dentro de esta clasificación, Gottlieb precisa que "Sinfonía de cuna" y "Preguntas a la hora del té" (ambas de la primera sección) son excepciones, ya que "pertenecen" en realidad al grupo de poemas satíricos y sarcásticos de la segunda. "Preguntas...", por ejemplo, al igual que "Oda a unas palomas" (de la segunda parte), se burla de "la presunción y mal gusto de la sociedad" (Gottlieb 29-31).

Ambas estudiosas destacan el uso de la rima asonante y la regularidad métrica presentes en las dos secciones iniciales. La primera consiste en poemas en hexasílabos ("Sinfonía de cuna"), eneasílabos ("Defensa del árbol") y otra vez hexasílabos ("Catalina Parra") antes de los cuatro textos en endecasílabos ya mencionados; en la segunda sección, se encuentran "Desorden en el cielo" (octosílabos), "San Antonio" (eneasílabos), "Autorretrato" (silva: heptasílabos y endecasílabos), "Canción" (octosílabos), y "Oda a unas palomas" y "Epitafio" (silvas con alguna irregularidad métrica, sobre todo en la primera). Convendría señalar, dentro del tradicionalismo, esta diversidad de metros, y apuntar particularmente que, después de los octosílabos populares o neopopulares de su primer libro, Cancionero sin nombre (1937), Parra tendió a "endecasilabarse" en la primera etapa de la escritura de Poemas y antipoemas, como volvería a hacerlo -después del versolibrismo de los antipoemas de 1954 y los octosílabos de La cueca larga (1958)- a partir de 
Versos de salón (1962) $)^{5}$. Por otra parte, tanto Rein como Gottlieb comentan la rareza de "Preguntas a la hora del té" en la sección inicial del libro, ya sea por cierta personalidad propia y autenticidad o por su "tono satírico". De todos modos, afirmar, como Gottlieb, que dos de los poemas de la primera sección "pertenecen" en realidad a la segunda no hace más que confirmar la extrañeza de la organización del libro de 1954.

Ahora bien, la idea de que no hay en la primera sección nada díscolo ni disonante, nada de sarcasmo ni de rebeldía, contradice la idea más matizada proferida por el propio Parra, que se refería en sus conversaciones

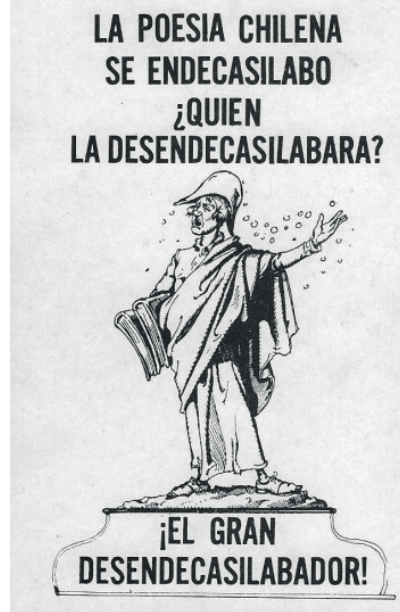

LA POESIA CHILENA SE ENDECASILABO ¿QUIEN con Leonidas Morales a una oscilación entre la nostalgia y la ironía: una ironía neorromántica, es cierto, pero de todos modos ironía. Federico Schopf, en una serie de estudios imprescindibles sobre Poemas y antipoemas, ha analizado la disonancia en esas primeras

$5 \quad$ Recuérdese el artefacto de 1972: "La poesía chilena se endecasilabó / ¿Quién la desendecasilabará? / ¡El gran desendecasilabador!” (Parra 428); y también la luminosa reflexión de Parra en sus conversaciones con Leonidas Morales, cuando este le señalara la "tendencia" hacia el endecasílabo en toda la antipoesía, pero su "desarrollo muy notable" en los Sermones y prédicas del Cristo de Elqui (a partir de 1977): "El octosílabo predominó en una época. Predominó hasta el momento en que se hizo la síntesis. Porque en una época estaba por una parte el octosílabo, como el mester de juglaría, y por otra parte el mester de clerecía, que era el de catorce sílabas. Ya está. Pero se produce la síntesis. Ocho más catorce, igual veintidós. Partido por dos, igual once. Síntesis, medio aritmético, que pasa a ser el metro no tan solo de la poesía, sino que del habla española. [...] Estos no son ni juglares ni clérigos, sino que es el común de los mortales ya, ¿entiendes? Una especie de nueva clase sociocultural. [...] ¡La nueva tribu, pues! Y lo que más se repite ahí, en esa jerga, son los grupos fónicos de once sílabas". Parra concluye que el poeta debe trabajar sobre esa "estructura subterránea" del endecasílabo "oral" en las sociedades hispanoparlantes, pero critica la tendencia generalizada entre los poetas de "embellecer" los endecasílabos. Vincula su propia utilización del metro con el pentámetro yámbico de Shakespeare y también con una lección que descubrió en Cervantes, sobre el paso del habla medieval al habla moderna, y que lo dejó "patitieso"...: "He hecho algunos pequeños descubrimientos. Por ejemplo, cómo empieza el Quijote. Con un octosílabo, y sigue con un endecasílabo. Empieza con Sancho, con el mundo de Sancho, con el idioma de Sancho: 'En-un-lu-gar-de-la-Man-cha, / de-cu-yo-nom-bre-no-quie-roa-cordarme"” (Morales 120-121). 
obras maestras de Parra (así las consideraba, en 1942, Tomás Lago): los largos poemas endecasílabos "Hay un día feliz", "Es olvido" y "Se canta al mar"'. En estos textos, Schopf estudia la representación del mundo rural, a través de recuerdos de la infancia y la adolescencia, como un espacio de felicidad y de armonía con la naturaleza y con el prójimo. La imagen del campo y del pueblo como espacios de felicidad correspondería en realidad, según Schopf, a cierta complejidad psíquica en el hablante de estos poemas, recién llegado del mundo rural a la gran ciudad: a su deseo o necesidad de "resguardo en una comunidad y una trascendencia" en cuya realidad "ya no cree" (189-190). Por eso, la mirada tradicional sobre el pueblo de la infancia está sombreada por una serie de disonancias, y sobre todo por el hecho de que el hablante lo reconstruye desde la ciudad en la que se ha acostumbrado a maneras radicalmente diferentes de relacionarse con el mundo (por algo, recuerda Schopf, Poemas y antipoemas comienza con un poema explícitamente urbano: "Una vez andando / Por un parque inglés..."). En efecto, estos tres poemas -notablemente "Hay un día feliz" y sobre todo "Es olvido"- están salpicados con "indicios que nos permiten corroborar -y reconstruir- la relativización básica de la afirmación aparente de que este mundo haya existido de esta manera en el pasado". Así sucede con una serie de frases "fuera de lugar", cuyo prosaísmo o coloquialismo perturban el estilo elevado, la carga nostálgica y la seriedad de las admoniciones morales, haciendo que el sentido oscile para el lector "entre la solemnidad y el ridículo, la proposición seria y la paródica". De este modo, por ejemplo, en "Es olvido", las "dos actitudes y modos de representación del poeta se entremezclan de tal manera que uno se pregunta qué impulso constituyente del mundo predomina en este poema: si aquel de la sublimación estética o aquel que -en este caso, implacablemente- la destruye" (191).

Es decir, para Schopf (y también para el propio Parra), no existe un tradicionalismo monolítico en estos tres poemas que tanto embelesaron a Tomás Lago (que no veía las disonancias) en su antología de 1942. En ellos

\footnotetext{
"En el claro de un realismo neo-romántico se cuentan cosas, se establecen asuntos de nuevo, entre vigentes símbolos ramados y gentiles alegorías. Allí sucede desde la restauración del poema métrico - cuya ausencia había terminado por hacernos sentir cuánto lo amábamoshasta la creación de un nuevo estado anímico, limpio y simple, sedante como un cielo lavado después de la tormenta. Leed 'Era un día Feliz' [sic] de Nicanor Parra y decidme si no está allí la poesía también, la poesía, todavía como en sus grandes días, con su gracia divina de ojos enamorados" (Lago 24-25).
} 
ya están operando las disonancias que luego se convertirán en centrales en la antipoesía. Por ello, es natural que Schopf los considere de la misma familia de "Preguntas a la hora del té", el otro poema endecasílabo de la primera sección de Poemas y antipoemas. Ya no se trata, en este, de reconstruir el júbilo ingenuo del niño que ve por primera vez el mar, ni la inocencia del primer amor, ni el ordenado mundo feliz de la familia, ni de rememorar con nostalgia la infancia y adolescencia perdida en versos que serán -según el color del cristal con que se les mira-serios o paródicos, solemnes o ridículos: "¡Buena cosa, Dios mío! nunca sabe / Uno apreciar la dicha verdadera, / Cuando la imaginamos más lejana / Es justamente cuando está más cerca" (Parra 12). Eso sí, "Preguntas..." también comunica un sentimiento del paso irremediable del tiempo y -a través de inquietudes metafísicas "insolubles a partir de las maneras en que las formula"- de una incapacidad de asirse al pasado: "Lo que se vio una vez ya no se vuelve / A ver igual, dicen las hojas secas". Al igual que en sus lecturas de "Es olvido" y "Hay un día feliz", Schopf hace hincapié en el carácter provinciano del sujeto que habla en "Preguntas...", ilustrándolo con una curiosa abundancia de detalles que corroborarían una imagen coherente del hablante -del personaje "parriano"elaborada a lo largo de Poemas y antipoemas:

El protagonista de "Preguntas a la hora del té" parece ya alguien que solo va de visita circunstancial al ambiente provinciano; probablemente exhibe en su vestimenta, en sus maneras y preocupaciones su roce con medios sociales y culturales más sofisticados. El propio poeta representa al protagonista por medio de una comparación con "una figura de cera", es decir, con un simulacro de la gran ciudad. Sus preocupaciones metafísicas -aunque utilice para ellas imágenes del mundo rural-quieren hacer manifiesta, a sí misma y a sus interlocutores de provincia, la formación que ha adquirido en universidades, viajes y salones. El personaje mismo es ya, en cierta medida, extraño a la sala provinciana en que intenta hacer un remedo (un tanto siútico) de un culto "five o' clock tea". El ambiente en que intenta reproducir esta "ceremonia" traiciona cierta degradación y pobreza provinciana: el personaje que se interroga sobre el ser de la realidad "mira a través de los visillos rotos" y consume, junto a los huéspedes, margarina, es decir, un producto industrial, un Ersatz y no la mantequilla producida artesanalmente en el campo. La presencia de margarina en la mesa provinciana es, además, un indicio del predominio creciente de la ciudad sobre el campo (Schopf 187). 
Resulta curioso imaginar hasta qué punto habría cambiado la recepción de su libro de 1954 si Parra hubiera decidido publicar solo la última sección: Antipoemas. Lo que se perdería, evidentemente, es una especie de muestra-más o menos cronológica- del proceso de búsquedas que condujo a la antipoesía. Como hemos visto, Schopf lee la tensión en la primera sección de Poemas y antipoemas como un fruto de la dialéctica arquetípicamente moderna entre el campo y la ciudad, que daba lugar a contrastadas actitudes y modos de representación, y que terminaba -en la sección antipoética, en textos como "El túnel"- en un rechazo de cualquier ilusión de valor en el espacio rural. William Rowe, en su ensayo "Hacia el poema como ameba...", ofrece una lectura complementaria a la de Schopf. Para él, las primeras secciones del libro "utilizan el método de moverse entre la dicción literaria y el habla coloquial, entre la 'poesía' y la 'antipoesía", un movimiento que cesa en la tercera parte del libro, donde Parra "abandona este doble registro y usa solamente materiales que podrían ocurrir en la conversación" $(150)^{7}$. La incorporación del habla coloquial tiene que ver con la disponibilidad -ajena a la poesía tradicionalde incorporar lo no-poético, es decir, remite a una "porosidad extrema del poema" que Rowe relaciona con una reflexión de Parra respecto al hombre -y el poeta- "como una ameba, capaz de recibir sustancias del ambiente a través de su membrana" $(154)^{8}$. El antipoema o poema-ameba que propone

\footnotetext{
Rowe puntualiza que los términos poesía y antipoesía "no son absolutos sino históricos", ya que "poesía, en este caso particular, se refiere a la rica herencia del romanticismo y modernismo, mientras que antipoesía alude a una práctica de escritura que parte del habla cotidiana" (150).

De nuevo la reflexión proviene de las Conversaciones... de Leonidas Morales, a quien Parra comentaba la insatisfacción que le había producido su primer libro, Cancionero sin nombre, y el aburrimiento que sentía al leer la poesía de esa época. Al examinar "en qué momento empezó a practicarse la poesía en esos términos", retrocedió en sus lecturas y topó primero con el Renacimiento y luego con la Grecia académica. Se sintió obligado a cambiar de rumbo en sus búsquedas: "Donde yo encontré vitalidad y razón de ser fue en la Edad Media, o sea, en el pueblo. Yo traté de ir incluso más lejos, y llegué hasta el hombre de las cavernas, pero todavía no entendía bien la cosa. Y dije, bueno, hay que retroceder más aún, y en esta regresión llegué a la célula, a la célula viva. Me dije que más atrás no se podría ir: si descompongo la célula, desaparece la vida. Me pareció que ese era el ladrillo fundamental de la vida. Me pregunté: ¿qué puedo decir yo realmente de lo que pueda responder? Bueno, que el hombre es una ameba que se nutre de lo que encuentra a su paso. Y entonces hice esta formulación: el hombre es una ameba gigante que se nutre de lo que encuentra a su paso. Y me pareció que esa frase respiraba, que esa frase vibraba, que era irrefutable y que el tono de esa frase había que llevarlo a otros textos" (Morales 83).
} 
Rowe ya no es un artefacto hermético, inamovible; elude "todo intento de marco", deja de ser un texto "acerca" de algo e invita a "una consideración acerca de los efectos negativos de aquella acción limitante" que consiste, por parte de los críticos, en poner círculos en torno a un poema, en fijar sus temas. El poema-ameba se abre al "afuera", al "discurrir poroso del habla", encarnando en la práctica la prédica del artefacto "TODO / ES POESÍA / menos la poesía" (168-169).

"Preguntas a la hora del té" ofrece a Rowe un ejemplo sugerente. El título en sí posee "una doble función de cerco y apertura". Por un lado, sirve para establecer un marco tradicional en torno a la escena representada. En este sentido, afirma Rowe, "las 'preguntas' serían las preguntas que el hablante articula (por ejemplo, 'Qué vale más, ¿el oro o la belleza?'), cuyo carácter proverbial les otorga un aire de seriedad pero que se revelan finalmente como fatuos clichés coincidentes con la mise-en-scène -de pequeñoburguesía decadente- del té y las cortinas de encaje agujereadas". Aparentemente, la ironía respecto a esa fatuidad presenta al lector una coartada o "lugar seguro" para distanciarse de la escena y sentirse superior a la divagación reflexiva del "señor desvaído": "En un momento dado el hablante contesta las preguntas y parece ofrecer a los lectores un lugar seguro fuera de la escena presentada: "No se sabe, la gente se lo pasa / construyendo castillos en la arena"' (154). En realidad, sin embargo, el lenguaje no permite ese distanciamiento; el lugar seguro está minado por la metáfora de los castillos de arena, cuyo "contenido" (referencia a la fatuidad de la especulación) tal vez convenza pero cuya forma "es no menos cliché que los clichés de los que se propone ponerse fuera". El interés del poema, según Rowe, estriba precisamente en esta negación de la posibilidad de un lugar seguro. El título "Preguntas a la hora del té" sirve como marco para cercar la escena, pero no otorga superioridad ni a la voz del poema ni al lector que se ciñe a ella:

A nivel formal las preguntas ofrecen disyunciones falsas -falsos "esto o lo otro"- dando la impresión de que todo puede ser resuelto en una manera u otra: la ilusión de que al descomponer las cosas a través del análisis es posible alcanzar el afuera. Es por esto que el poema se interroga a sí mismo -he aquí el otro significado del título- sin encontrar un lugar estable desde donde hacerlo. Es por lo tanto una tergiversación pretender, como varios críticos pretenden, que los poemas de Parra constituyen una diatriba contra la pequeña burguesía. A pesar de que el poeta se haya interesado al inicio de su carrera en la tradición irónica de la poesía inglesa representada por 
Eliot y Auden, no se decide finalmente por esa actitud de superioridad. En este sentido, el poema es más radical que el Prufrock de Eliot, al que claramente imita $(155)^{9}$.

Dudo que se trate de una mayor radicalidad. Lo cierto es que, a diferencia de un monólogo dramático como "The Love Song of J. Alfred Prufrock", la distancia implícita establecida entre el autor implícito y el hablante-personaje del texto resulta borrosa. El que habla -o los que hablan- en el poema de Parra no llega a los niveles del absurdo del texto de Eliot (piénsese, por ejemplo, en la pregunta final de un Prufrock ya resignado a su ridículo patetismo: "Do I dare to eat a peach?”, “¿me atrevo a comer un melocotón?”). Por otra parte, Rowe se refiere al hablante de "Preguntas..." como si hubiese una sola voz en el poema. Pero, ¿qué relación hay entre el yo observador que habla y el objeto de su observación: ese "señor desvaído", que mira a través de los visillos rotos y al que el hablante compara despectivamente con la "figura de un museo de cera"? Si no me equivoco, las preguntas formuladas pertenecen al señor observado y figuran en el poema filtradas por la voz del hablante. ¿Entendemos que este ha sido capaz de meterse en la cabeza del "señor", de leer sus pensamientos? ¿Es tal la complicidad entre los dos? Por otra parte, ¿no es el hablante del poema el responsable de los comentarios sobre el espacio (sobre la campana, la atmósfera, las tostadas, la margarina) y de las afirmaciones sentenciosas ("la gente se lo pasa / construyendo castillos en la arena") que funcionan, aparentemente, como respuestas a las preguntas del "señor"? Lo importante es, como Rowe ha mostrado, que estos comentarios $\mathrm{y}$ aseveraciones son del mismo tono que el de las preguntas, y la pobreza tópica de sus metáforas impide salir de las dudas y del impostado lenguaje poético del otro. Por otra parte, si coexisten en el texto estas dos voces, ¿dónde se sitúa la tercera voz, la del autor implícito? ¿Debemos entender que rechaza igualmente a ambas? A diferencia de "The Love Song...”, el poema no permite que situemos a esa tercera voz, por mucho que los demás poemas que escribió Parra en Oxford rechazan tajantemente la reflexión metafísica ${ }^{10}$.

\footnotetext{
Rowe reconoce, eso sí, que en otro sentido el poema alcanza una resolución final mediante la "voz eliotesca" de "Lo que se vio una vez ya no se vuelve / A ver igual, dicen las hojas secas" (155).

10 Sobre el rechazo a la metafísica en el Parra de los años de Oxford, bastaría con volver a "Advertencia al lector", pero hay un testimonio de Alejandro Jodorowsky que sirve como corroboración. Después de regresar a Chile en 1951, Parra colaboró con Jodorowsky y
} 
Curiosamente, el único punto de fuga que se abre en "Preguntas a la hora del té" - probablemente de manera inconsciente por parte del autor-, es la maravillosa fealdad del chilenismo "chépica", que desentona con el aire apagado y convencionalmente lírico (¿machadiano?) del resto del poema.

\section{EN LA CIUDAD DE LAS IGLESIAS SOÑADORAS. UNA LECTURA INGLESA}

Federico Schopf analiza "Preguntas a la hora del té" en relación con los tres poemas largos de la primera sección de Poemas y antipoemas, equiparando sus respectivas miradas sobre el paso del tiempo, la infancia y la emigración del campo a la ciudad. Me parece más factible pensar que, dentro de la primera sección, se emparienta con "Catalina Parra" en el sentido muy concreto de que los dos son poemas escritos desde el extranjero: este fue escrito en Estados Unidos (1943-1945); "Preguntas...", por su parte, proviene con casi toda seguridad de los años de Parra en Oxford (1949-1951). Schopf, de acuerdo con su lectura "chilena" del poema, lee la referencia a la "hora del té" como una muestra de la pretensión y la ostentación de un sujeto chileno recién llegado de la provincia a la ciudad, como un rasgo de su siutiquería; a fin de cuentas, en Chile solo la elite de la sociedad, o los aspirantes a esa elite,

Enrique Lihn en los Quebrantahuesos, y Parra pidió que Jodorosky organizara y mecanografiara el manuscrito "Notas al borde del abismo" (anunciado por Lihn en su estudio sobre Parra en Anales de la Universidad de Chile, en 1951), una especie de "diario literario": "Parra nunca las publicó, ni volvió a hablar de ellas. Con una cultura universitaria superior a la de sus antecesores, todos autodidactas, se había especializado en el estudio del Círculo de Viena y la obra de Ludwig Wittgenstein. Tanto le interesaba Galileo como Kafka, de quien admiraba, por encima de todo, su diario. Tenía su propia interpretación de la célebre frase del Tractatus, 'De lo que no se puede hablar hay que callar'. Para él, la metafísica, la religión, eran terrenos vedados. También la expresión de sentimientos personales. 'El poeta no se debe exhibir: debe mover los hilos desde afuera"” (Jodorowsky 264-265). Es decir: habría que callar las preguntas "a la hora del té", distanciarse de los lamentos. Ahora bien, en "The Love Song of J. Alfred Prufrock", "Portrait of a Lady" y "Conversation Galante", así como en "Soliloquio del individuo" y "Conversación galante", se percibe claramente el carácter dramático del texto, el hecho de que quien habla no es el poeta, que este está detrás, moviendo los hilos. En "Preguntas a la hora del té", no hay motivos textuales para plantear la existencia de un poeta-titiritero de esta índole. 
hablarían de tomar el té en vez de la "once". Aquí, en cambio, ensayaremos una lectura "inglesa", que sitúe la voz y el personaje del poema en Oxford.

"Preguntas a la hora del té" presenta a un personaje ("este señor desvaído"), un espacio (visillos rotos, campanas, tostadas, té) y una concentración de preocupaciones metafísicas que no existen en otros textos de Poemas y antipoemas. El último verso ("todo envuelto en una especie de niebla") nos señala el motivo: la procedencia inglesa del poema. La descripción arquetípica de Oxford, como la ciudad de las "dreaming spires" -agujas de iglesia soñadoras-, proviene del poema "Thyrsis", escrito en 1866 por Matthew Arnold. Ya entonces la situación geográfica de Oxford -una ciudad atravesada por los ríos Cherwell y Támesis-, combinada con la utilización masiva de carbón en las chimeneas de la veintena de "Colleges" de la Universidad, propiciaba una niebla trémula que envolvía las distintas iglesias de la ciudad, haciéndolas "soñar". A mediados del siglo XX, debido a las emisiones de la Oxford Power Station -la central eléctrica de carbón fundada a orillas del Támesis en 1892-, al ir y venir de las locomotoras de vapor y al aumento significativo de la población estudiantil, la contaminación atmosférica había crecido exponencialmente y ya dejaba huellas muy tangibles en la descoloración de la piedra caliza de los Colleges (Viles 359-371). La niebla se había convertido en una constante de la vida de Oxford, y seguiría siéndolo hasta la puesta en marcha del Clean Air Act de 1956. Así lo vivió Parra entre 1949 y 1951, y no es casual que este haya barajado el título de "Nebulosa 1950" para sus poemas escritos en Oxford"

La niebla le llegaba también a través de las lecturas. Resulta curioso que Parra haya comentado la importancia que tuvieron para él, en esos años, John Donne y William Blake, pero que apenas ha hablado del impacto -mucho más intenso, seguramente, y más cercano- que deben de haberle provocado poetas del siglo XX como Ezra Pound, W.H. Auden y sobre todo T.S. Eliot. La afirmación de Rowe - de que "Preguntas a la hora del té" imita "The Love Song of J. Alfred Prufrock"- ${ }^{12}$ es, por supuesto, una exageración,

11 A su regreso a Chile, en 1951, Parra planteaba la posibilidad de titular su nuevo libro Oxford 1950. En alguna entrevista ha comentado que Nebulosa 1950 era otro candidato en esos años. Lo cierto es que emplearía este último título para la primera sección de su libro Poesía política de 1983, una sección que incluía solamente el poema "Mil novecientos treinta", que fue escrito en Oxford.

12 Recuérdense las palabras exactas de Rowe: "el poema es más radical que el Prufrock de Eliot, al que claramente imita". 
pero es más que probable que Eliot esté allí presente en el poema de Parra. A fin de cuentas, en el otro texto en endecasílabos que escribió en Oxford, "Conversación galante" -que se publicaría más de una década más tarde en Versos de salón-, el diálogo con el poema "Conversation Galante" de Eliot es notorio (Binns 66-70, 236).

"Conversación galante" formó parte del primer libro del norteamericano, Prufrock and Other Observations (1917), que se iniciaba con dos célebres y relativamente extensos poemas: "The Love Song of J. Alfred Prufrock" y "Portrait of a Lady". No hay imitación por parte de Parra, pero convendría señalar que los dos son textos marcados por el paso del tiempo, y por la personalidad fatua e indecisa de sus protagonistas ${ }^{13}$. En ese sentido, hay claros paralelismos con "Preguntas a la hora del té". El personaje mostrado por Parra es un "señor desvaído", parecido a una "figura de un museo de cera", un ser de identidad informe, deshumanizada, desdibujada (a fin de cuentas, todo se desdibuja bajo le niebla); Prufrock, a lo largo de su poema, falla en sus intentos de formular la gran pregunta que le obsesiona y termina aceptando su naturaleza insustancial, pusilánime, imaginándose -a ojos de los demáscomo un insecto clavado con un alfiler contra la pared ${ }^{14}$; el protagonista masculino de "Portrait of a Lady", por su parte, al no atreverse a responder con honestidad a las tristes reclamaciones de su anfitriona, al escabullirse en cada momento en vez de confesar su indiferencia, también pierde espesura humana, se animaliza, autorretratándose como loro, mono y oso danzante ${ }^{15}$.

13 "Portrait of a Lady" lleva como epígrafe la célebre cita de El judio de Malta que Parra rescata con frecuencia en su conversación (y recordó, seguramente, durante su conversación con Tennant)-, "Thou hast committed / Fornication: but that was in another country, / And besides, the wench is dead"; "Tú has cometido - / fornicación: pero fué en otro país / y además, la moza ha muerto" (Eliot 32).

$14 \quad$ "And I have known the eyes already, known them all - / The eyes that fix you in a formulated phrase, / And when I am formulated, sprawling on a pin, / When I am pinned and wriggling on the wall, / Then how should I begin / To spit out all the butt-ends of my days and ways"; "Y he conocido ya los ojos, los conozco todos - / los ojos que te miran fijos en una expresión formulada, / y cuando esté formulado, despatarrado en un alfiler, / cuando esté clavado y retorciéndome en la pared, / ¿cómo empezaría entonces / a escupir todas las colillas de mis días y maneras?" (Eliot 29).

15 "For everybody said so, all our friends, / They all were sure our feelings would relate / So closely! I myself can hardly understand. / We must leave it now to fate. / You will write, at any rate. / Perhaps it is not too late. / I shall sit here, serving tea to friends'. // And I must borrow every changing shape / To find expression ... dance, dance / Like a dancing bear, / Cry like a parrot, chatter like an ape. / Let us take the air, in a tobacco trance"; "Porque lo 
Además, ambos poemas están asediados por la niebla: "the yellow fog that rubs its back upon the window-panes" en la tercera estrofa de "The Love Song..." 16. "the smoke and fog of a December afternoon" del primer verso de "Portrait of a Lady", que va constituyendo la escena para la interacción entre el yo y la dama ${ }^{17}$. Los dos poemas, por otra parte, crean como espacios interiores salones pertenecientes a la alta sociedad en los que Prufrock -en un célebre estribillo- está rodeado de mujeres que van y vienen hablando de Miguel Ángel ("In the room the women come and go / Talking of Michelangelo"), mientras que el protagonista de "Portrait..." se encuentra a solas, en tres ocasiones (las tres partes del poema), con la dama del título. En ambos espacios se toma té. La "dama" termina reconciliándose con el hecho de que no prosperará la relación con el hablante y que pasará toda su vida "serving tea to friends" (sirviendo el té a los amigos); Prufrock, por su parte,sufre sus dudas existenciales y su inseguridad ante la mujer que parece atraerle, en un entorno marcado por la ceremonia del té: "There will be [...] time for you and time for me, / And time yet for a hundred indecisions, / And for a hundred visions and revisions, / Before the taking of a toast and tea"; "Should I, after tea and cakes and ices, / Have the strength to force the moment to its crisis?"; "And would it have been worth it, after all, / after the cups, the marmalade, the tea, / Among the porcelain, among some talk of you and me, / Would it have been worth while, / To have bitten off the matter with a smile, / To have squeezed the universe into a ball / To roll it toward some overwhelming question" $" 18$.

decían todos, todos nuestros amigos, / decían que sin duda nuestros sentimientos tendrían / una relación ¡tan estrecha! Yo misma casi no lo entiendo. / Ahora tenemos que dejárselo al destino. / De todos modos, me escribirá. / Quizás no sea demasiado tarde. / Yo seguiré aquí sentada, sirviendo el té a los amigos'. // Y tengo que pedir prestada toda forma cambiante / para encontrar expresión... danzar, danzar / como un oso danzante, / chillar como un loro, charlotear como un mono. / Tomemos el aire, en un éxtasis de tabaco" (Eliot 35).

16 "La niebla amarilla que se restriega el lomo en los cristales de las ventanas, / el humo amarillo que se restriega el hocico en los cristales de las ventanas, / metió la lengua lamiendo los rincones del atardecer, / se demoró en los charcos quietos sobre los sumideros, / dejó que le cayera en el lomo el hollín que cae de las chimeneas, / resbaló por la azotea, dio un brinco repentino, / y, viendo que era una suave noche de octubre, / se enroscó una vez en torno a la casa y se quedó dormida" (Eliot 28).

17 "Entre el humo y la niebla de una tarde de diciembre / haces que la escena se arregle sola" (Eliot 32).

18 "[Habrá] tiempo para ti y tiempo para mí, / y tiempo aun para cien indecisiones, / y para cien visiones y revisiones, / antes de tomar té con tostadas”; “Debería yo, después del té 
A diferencia de los personajes de estos dos poemas de Eliot, que se muestran acompañados en el momento de la ceremonia del té -por mucho que la interacción con el otro resulte vacua o evasiva-, el "señor desvaído" de Parra está a solas, aislado de los demás. Es un objeto de interés únicamente para la mirada analítica del hablante. Del acto social de tomar el té ya no queda ni la ilusión de estar compartiendo con el prójimo; las reflexiones metafísicas son un callejón sin salida, y cada mención del espacio no hace más que agravar la sensación de degradación. El señor desvaído mira a través de "visillos rotos": no sorprenderá la imagen a cualquiera que haya experimentado los habituales "students' digs" de Oxford, alojamientos baratos en casas particulares a cuyos dueños ni se les ocurriría gastar dinero en arreglar comodidades destinadas al maltrato por parte de los jóvenes de turno. El sonido desde lejos (atenuado, tal vez, por la niebla) de la campana - una de las tantas campanas de esas iglesias soñadoras de la ciudad-evoca el pasado, abriendo y cerrando nuevas heridas. La atmósfera "cansada / de ceniza, de humo, de tristeza" y el paisaje otoñal de las hojas muertas conducen a la toma de conciencia tan tópica que ya se ha comentado: "lo que se vio una vez ya no se vuelve / a ver igual". En fin, es como si la anulación del yo (oculto sistemáticamente tras las oraciones impersonales: "se oye"; "no se sabe"; "se respira"...), y luego, en los versos finales, la inercia rutinaria de la ceremonia del té, la ausencia paralizante de un verbo principal, y la niebla que cierra el poema sirvieran, por decirlo con palabras de María Luisa Bombal, para "presta[r] a las cosas un carácter de inmovilidad definitiva".

\section{LA ÉPOCA DE LA AUSTERIDAD}

"Preguntas a la hora del té" es uno de los poemas ingleses de Parra. Allí está la niebla propia de la contaminación atmosférica que vivió en Oxford (sobre todo en la particularmente helada primavera que hubo en 1950); allí están las lecturas que hizo en Oxford de Eliot (aunque las nieblas y los tés del norteamericano

con pastas y helados, / tener la energía de forzar el momento hasta su crisis?"; "Y habría valido la pena, después de todo, / después de las tazas, la mermelada, el té, / entre la porcelana, entre un poco de charla tuya y mía, / habría valido la pena, / descabezar de un mordisco el asunto con una sonrisa, / apretar el universo en una bola / echándolo a rodar hacia alguna pregunta abrumadora" (Eliot 28; 30). 
eran anteriores a su llegada a Inglaterra). Allí están, también, las huellas de su residencia en un país profundamente golpeado por la experiencia de la Segunda Guerra Mundial y por la conciencia de estar enfrentándose, en la recién inaugurada Guerra Fría, a una lucha potencialmente aún más destructiva, que tenía sus prolegómenos en la Guerra de Corea (1950-1953), en la que participaron casi cien mil soldados británicos ${ }^{19}$. Parra vivió los inicios no solo de la Guerra Fría sino también de la Guerra Fría Cultural ${ }^{20}$. Habrá seguido, en la prensa británica, las denuncias sistemáticas de las atrocidades de Stalin, el amable "Uncle Joe" de cinco años antes, vilipendiado ahora como monstruo; llegó a Inglaterra poco después de la publicación de 1984 y en su segundo año en Oxford habrá leído las necrologías sobre Orwell, un autor convertido de inmediato, a pesar de sus largos años de militancia anticapitalista, en el ideólogo liberal pero sobre todo antitotalitario por excelencia de la Guerra Fría $^{21}$; habrá visto, además, la aparición de libros como The God that Failed (1950), una colección de ensayos escritos por seis intelectuales prestigiosos (entre ellos Arthur Koestler, André Gide y Stephen Spender) que habían sido comunistas o compañeros de viaje del comunismo y relataban la historia de su militancia en términos de fe, crisis de la fe y apostasía. Por otra parte, la postguerra estaba precipitando el desmantelamiento del Imperio, y Parra

19 Winston Churchill, en el prefacio de The Gathering Storm (1948), primer volumen de su obra magna sobre la Segunda Guerra Mundial, hablaría de esta como una guerra "innecesaria", pero veía la mayor tragedia del conflicto en el hecho de que, a pesar de todos los sacrificios y la victoria, "aún no hemos encontrado ni la Paz ni la Seguridad, y estamos atrapados por peligros aún peores que los que hemos superado" "There never was a war more easy to stop than that which has just wrecked what was left of the world from the previous struggle. The human tragedy reaches its climax in the fact that after all the exertions and sacrifices of hundreds of millions of people and of the victories of the Righteous Cause, we have still not found Peace or Security, and that we lie in the grip of even worse perils than those we have surmounted" [1948, iv-v]).

$20 \quad$ Véase el libro de Frances Stonor Saunders Who Paid the Piper?: CIA and the Cultural Cold War (1999), retitulado en Estados Unidos como The Cultural Cold War: The CIA and the World of Arts and Letters (2000), y publicado en la editorial madrileña Debate como La CIA y la guerra fría cultural (2001).

21 "Poco después de la muerte de Orwell, en 1950, [el escritor y agente secreto de la CIA] Howard Hunt envió a [Carleton] Alsop y a [Finis] Farra a Inglaterra para que hablasen con Sonia, la viuda del escritor. No fueron allí para consolarla, sino para convencerla de que firmase el contrato de cesión de los derechos de Animal Farm (Rebelión en la granja). Ella lo hizo, no sin antes hacerles prometer que organizarían un encuentro con Clark Gable. 'De esta [visita] -escribió Howard Hunt- procede la película de dibujos animados Animal Farm, que la CIA financió y distribuyó por todo el mundo"” (Stonor Saunders 410). 
habrá presenciado la ardua pero definitiva toma de conciencia de que Gran Bretaña no volvería a ser la potencia que fue. En 1947, India consiguió su independencia y entró en vigor la nueva Constitución del país en enero de 1950, cuando Parra estaba ya en Oxford. Además, en esas fechas, a pesar de la eclosión de Dylan Thomas - cuya poesía visionaria y a menudo grandilocuente no podía seducirle-, las letras andaban también de capa caída, y en ese sentido Parra tuvo la mala suerte de llegar a un país donde se estaba viviendo -según el escritor Philip Hobsbaum- el peor abatimiento de la historia de la poesía británica, "the worst doldrums English verse has known" (Tolley 279).

Es decir, Parra vivió dos años en un país traumatizado y con miedo. W.H. Auden habló, en un largo poema de 1947, de The Age of Anxiety; Michael Sissons y Philip French, por su parte, bautizarían el período 1945-1951 como "the Age of Austerity". Marcados por la angustia y la austeridad, los primeros años de la posguerra habían visto, no obstante, grandes conquistas sociales. El gobierno laborista de Clement Attlee (quien derrotó a Churchill en las elecciones generales de 1945, volvió a ganar en 1950, pero aguantó en el poder solo hasta octubre de 1951) ${ }^{22}$ fundó la National Health Service y desarrolló un ambicioso programa de nacionalizaciones (el Banco de Inglaterra, el carbón, los ferrocarriles, la electricidad, el gas, el hierro...), pero la necesidad de reacomodar la economía del país a tiempos de paz y el crecimiento exponencial de la deuda contratada con Estados Unidos y Canadá impidieron una salida rápida de la crisis socioeconómica. Cuando llegó Parra a Inglaterra en septiembre de 1949, aún existía el racionamiento inaugurado a comienzos de 1940, que había sido mantenido por el partido laborista en parte por necesidad, pero en parte también para evitar un aumento de las desigualdades sociales. Seguirían racionados, mientras Parra vivía en Oxford: la leche hasta enero de 1950; la gasolina y las comidas en restaurantes hasta mayo de 1950; los huevos y el jabón hasta septiembre de 1950; el té hasta octubre de 1952; los caramelos y el chocolate hasta febrero de 1953; los huevos hasta marzo de 1953; el azúcar hasta septiembre de 1953; la mantequilla, el queso y la margarina hasta mayo de 1954; y la carne hasta el

$22 \quad$ Atlee volvió a ganar en las elecciones generales del 23 de febrero de 1950, pero con una mayoría demasiado escasa para sobrevivir la legislatura. En palabras del periodista y dramaturgo Michael Frayn, después de esas elecciones, los laboristas se arrastraban como un animal viejo y maltrecho, mordiendo sus propias heridas: "they dragged themselves through their las painful months in the spring of summer of 1951 like an old, wounded animal, biting at its own injuries" (en Sissons y French 321). 
4 de julio de 1954. Ahora bien, el azúcar y la mantequilla eran los alimentos básicos que sufrían el mayor recorte, aunque en el caso de la mantequilla la existencia de la margarina (racionada de manera mucho más laxa) paliaba la falta. Así, por ejemplo, comparado con el abastecimiento de 1934-1938, en 1949 (año de la llegada de Parra) la disponibilidad de mantequilla era de $56 \%$; la de carne de $68 \%$; la de azúcar de $90 \%$; y la de té de $89 \%$ (ZweinigerBargielowska 32, 36).

Schopf, en su análisis de "Preguntas a la hora del té", señala la presencia de la "margarina, es decir, un producto industrial, un Ersatz y no la mantequilla producida artesanalmente en el campo" y la interpreta como un indicio en Poemas y antipoemas del "predominio creciente de la ciudad sobre el campo" ${ }^{23}$. Creo, más bien, que la margarina, el té y la atmósfera depresiva constituyen un señalamiento, dentro del poema, de la experiencia concreta de la traumática posguerra, de la época de austeridad vivida por Parra en una Inglaterra sin mantequilla, sin imperio y sin esperanza.

\section{CONCLUSIÓN}

El interés primordial de "Preguntas a la hora del té" se encuentra, me parece, en su capacidad de transmitirnos, en su atmósfera sombría, la experiencia de Oxford de Nicanor Parra, el trasfondo vivencial de al menos tres de sus grandes antipoemas: "Advertencia al lector", "Soliloquio del individuo" y "Mil novecientos treinta". Fue una experiencia decisiva, sí, gracias a sus lecturas de Donne y Blake, de Eliot, Auden y Pound, pero vivir la Edad de la Angustia y la Austeridad, convivir con la escasez, la margarina, el fin del Imperio, el té sin azúcar, el comienzo de la Guerra Fría y, en general, con la profunda crisis de identidad que estaba experimentando el Reino Unido, debe de haber impregnado y contagiado a Parra con la tristeza y el abatimiento que abundan en este poema.

23 Sobre el auge de la margarina como sustituto, Ersatz, de mantequilla en Europa, durante la Primera Guerra Mundial, véase el artículo "Operation Margarine” de Nina Martyris (2014). 


\section{BIBLIOGRAFÍA}

Binns, Niall. Nicanor Parra o el arte de la demolición. Valparaíso: UV, 2014.

Churchill, Winston S. The Second World War. The Gathering Storm. Cambridge, MA: The Riverside Press, 1948.

Eliot, T. S. Poesías reunidas. 1909-1962. Trad. e introducción de José María Valverde. Madrid: Alianza, 1999.

Gottlieb, Marlene. No se termina nunca de nacer: La poesía de Nicanor Parra. Madrid: Playor, 1977.

Jodorowsky, Alejandro. La danza de la realidad. Madrid: Siruela, $7^{\mathrm{a}}$ ed., 2011.

Lago, Tomás (ed.). Tres poetas chilenos. Santiago: Cruz del Sur, 1942.

Martyris, Nina. "Operation Margarine. Tracing the wartime rise of ersatz butter". Harper's Magazine (mayo 2014). http://harpers.org/blog/2014/05/operation-margarine/

Morales, Leonidas. Conversaciones con Nicanor Parra. Santiago: Ediciones Universidad Diego Portales, 2014 [1991].

Parra, Nicanor. Obras completas \& algo + (1935-1972). Barcelona: Galaxia Gutenberg/ Círculo de Lectores, 2006.

Rein, Mercedes. Nicanor Parra y la antipoesía. Montevideo: Universidad de la República, 1970.

Rowe, William. "Hacia el poema como ameba: Poemas y antiopemas de Nicanor Parra". Hacia una poética radical. Ensayos de hermenéutica cultural. Beatriz Viterbo/Mosca Azul: Rosario, 1996: 145-171.

Schopf, Federico. Del vanguardismo a la antipoesía. Ensayos sobre la poesía de Chile. Santiago: LOM, 2000.

Sissons, Michael y Philip French (eds.). The Age of Austerity, 1945-1951. Oxford, Oxford University Press, 1986 [1964].

Stonor Saunders, Frances. La CIA y la guerra fría cultural. Madrid: Debate, 2001.

Tennant, J.S. "Letter from Chile. Jig-making with Nicanor Parra”. Poetry Nation Review (Cambridge, Inglaterra) 220 (nov.-dic. 2014): 7-8.

Tolley, A. Trevor. The Poetry of the Forties. Manchester: MUP, 1985.

Viles, Heather. “'Unswept stone, besmeer'd by sluttish time'. Air Pollution and Building Stone Decay in Oxford, 1790-1960". Environment and History 2: 3 (octubre 1996): 359-372. http://www.environmentandsociety.org/node/2905.

Zweiniger-Bargielowska, Ina. Austerity in Britain: Rationing, Controls, and Consumption, 1939-1955. Oxford: OUP, 2000. 